\title{
CO-CREATION WORKSHOP FOR INTERFACE DESIGN - DESIGNING INNOVATIVE HMI FOR AUTOMATED VEHICLES
}

\author{
WORKSHOP DE COCRIAÇÃO PARA DESIGN DE INTERFACE - PROJETANDO \\ HMI INOVADORAS PARA VEÍCULOS AUTOMATIZADOS
}

\author{
Manuela Quaresma ${ }^{1}$, D.Sc. \\ Isabela Motta ${ }^{2}$, Bach. \\ (1) LEUI | Laboratório de Ergodesign e Usabilidade de Interfaces \\ PUC-Rio | Pontifícia Universidade Católica do Rio de Janeiro \\ mquaresma@puc-rio.br \\ (2) LEUI | Laboratório de Ergodesign e Usabilidade de Interfaces \\ PUC-Rio | Pontifícia Universidade Católica do Rio de Janeiro \\ isabela.canellas@gmail.com
}

\begin{abstract}
Interface design, Co-creation, Brainstorming, Automated vehicles, Human-machine interface The increasing growth in the development of new technology is changing the way users interact with products. Thus, designers must re-think the human-machine interfaces (HMI) for communicating information regularly. Co-creation the process of joint creation of users and designers - is an approach to product and experience development that can substantially benefit the generation of innovative product proposals. The present paper aims to assess the feasibility of co-creation workshops for the development of proposals for interfaces of Artificial Intelligence derived products through a case study on interfaces for autonomous vehicles. For this purpose, two sessions of co-creation workshops using group brainstorming techniques were conducted with undergraduate and graduate Design students and professors, who are specialists in interaction and information design. The results showed that the interfaces proposed by the designers were communicated information in a wide range of ways, making use of existing technologies to present messages in an innovative manner, meeting autonomous vehicles' users' needs.

Design de interface, Cocriação, Brainstorming, Veículos automatizados, Interface humano-máquina O rápido desenvolvimento de novas tecnologias está mudando a forma como usuários se relacionam com os produtos. Assim, é necessário que os designers repensem as interfaces de comunicação humano- máquina constantemente. A cocriação - processo de criação coletiva envolvendo usuários e desenvolvedores - é uma abordagem que oferece diversos benefícios para geração de propostas inovadoras. Este artigo tem como objetivo explorar a aplicabilidade de um workshop de cocriação na produção de propostas de interfaces para produtos derivados de sistemas de inteligência artificial, por meio de um estudo de caso sobre interfaces de carros autônomos. Para isso, foram realizadas duas sessões de um workshop de cocriação com alunos e professores de graduação e pós-graduação em Design, especialistas em design de interação e de informação, utilizando a técnica de brainstorming em grupo. Os resultados mostram que as interfaces propostas pelos designers foram diversificadas na forma de comunicação de informação, utilizando tecnologias existentes para apresentar mensagens de uma forma inovadora e adequada às necessidades dos usuários de carros autônomos.
\end{abstract}

\section{Introduction}

Artificial intelligence systems have evolved and are capable of performing a wide range of activities. According to David Coplin, CEO of Microsoft UK, "This technology $[\mathrm{AI}]$ will change how we relate to technology. It will change how we relate to each other. I would argue that it will even change how we perceive what it means to be human." (INSIDER, 2016). The advancement of these systems makes it possible to develop products that may revolutionize the way users perform tasks, such as virtual assistants, robots in industries, and automated vehicles, that are already a reality and which the development is progressively evolving.

Currently, voice assistants such as Alexa can already perform over 30,000 skills, allowing users to perform tasks such as shopping or playing games through voice (STATISTA, 2018). Another type of system with artificial intelligence in expansion is the robots, which should revolutionize even more the 
PUC-Rio Pontifícia Universidade Católica do Rio de Janeiro Departamento de Artes \& Design | PPGDesign

work in industries. CoBots - Collaborative Robots are already able to recognize human movements and learn new commands in seconds, and it is expected that 150,000 units will be in activity by 2020 (TRADE MACHINES, 2019). Finally, fully automated vehicles, which will change the way drivers relate to automobiles, are already being developed and are expected to reach the market around 2030 (FROST and SULLIVAN, 2018).

Advances in artificial intelligence technology are changing the products with which users perform tasks. Thus, these advances also modify the relationship between users and products, changing the roles of users and systems in interaction, and the way information is communicated. Therefore, it is essential that interaction designers are aware of such changes in order to make the products' interfaces appropriate to the new dynamics of human-computer interaction. Several available creation methods are tools for designers to accomplish this task. This article presents the benefits of co-creation methods in the generation of interface proposals for innovative products.

\section{Co-creation and brainstorming for innovation}

The term co-creation can be broadly understood as the act of creating collectively, that is, creativity exercised by two or more people (SANDERS and STAPPERS, 2008). Currently, the word is commonly used to describe creative processes in which professionals responsible for product development, interactions, services, etc. collectively create with users and/or other stakeholders.

According to Prahalad and Ramaswamy (2004), cocreation is about creating joint value between companies and consumers, defining problems, and finding solutions in collaboration, through continuous dialogue in environments of innovative experience for new experiences of co-creation.

Sanders and Stappers (2008) argue that in the codesign process, - understood by the authors as "the creativity of designers and people not trained in design working together in the design development process" (SANDERS and STAPPERS, 2008, p. 6) the actors in the group have new roles to play. The end-user, who will eventually benefit from the design process, is placed in the position of the expert of his experience. The researcher and the designer contribute to the process of gathering insights, supporting the user with tools for ideation and expression, and collaborating with their design skills in the process of creating ideas (SANDERS and STAPPERS, 2008).

Several examples of products and services illustrate the value of co-creation processes for innovation. In 2008, Starbucks developed the

MyStarbucksIdea.com website, a platform on which the company's consumers could share their ideas and experiences with Starbucks (RAMASWAMY, 2011). Every month, some employees reviewed and, if appropriate, applied some of the ideas. Similarly, the French telecom company Orange created the IdClic platform, a website where company employees could share their ideas (RAMASWAMY, 2011). Over five years, more than 100,000 ideas were generated, of which 10,000 were implemented and resulted in more than 900 million euros in earnings and savings for the company. Likewise, the glass and ceramics company Corning Inc., in addition to uniting its engineers with users to develop solutions for different use cases, has also entered into partnerships with several companies, such as Sharp, Volkswagen, and even Johns Hopkins University (TURIERA and CROS, 2013).

There are several platforms for co-creation, either virtual or physical. In terms of physical interaction platforms, design workshops for co-creation can bring several benefits. Design workshops are a form of participatory design that consolidates co-creation methods in organized sessions (MARTIN and HANINGTON, 2012). These workshops bring together participants - designers, users, and other stakeholders - to carry out intense creative activities focused on solving a problem, contributing to the creation of solutions (MARTIN and HANINGTON, 2012). According to the authors, design workshops can include simple tools, allowing participants to create models/prototypes or drawings to illustrate solutions to a design problem.

In design workshops, group brainstorming is one of the most well-known and widely used co-creation techniques. Brainstorming is "an individual or group method for generating ideas, increasing creative efficacy, or finding solutions to problems" (WILSON, 2013, p. 16). Osborn (1962) states that the principle of brainstorming consists in the suspension of judgment in the generation of ideas: “(...) one must 'connect' once the spirit of judgment and again that of imagination, instead of simultaneously thinking, not only critically but imaginatively" (OSBORN, 1962, p. xxv). According to the author, the generation of free-of-judgment 
ideas in a brainstorming process favors creativity and the number of resulting ideas.

The basic group brainstorming procedure consists of four steps, according to Wilson (2013, p. 16):

1. "Selecting a group of three to ten participants with different backgrounds.

2. Posing a clear problem, question, or topic to the group.

3. Asking the group to generate solutions or ideas with no criticism or attempts to limit the type and number of ideas. This is the "divergent" phase in which you want as many ideas as possible without any censorship.

4. Discussing, critiquing, and possibly prioritizing the brainstorming results for later action. This last step is often called the 'convergent' phase where there is a winnowing of all the ideas into the ones that are judged as most applicable to a problem."

Group brainstorming brings several benefits for the creation of ideas and can contribute to an increase of new, more innovative products powered by novel technologies. Firstly, brainstorming enables a large number of ideas. According to Osborn (1962), the amount of ideas generated is vital for the creative processes because the first ideas are generally not the best ones. The author also points out that only $10 \%$ of the ideas created in ideation processes are of higher quality. Thus, brainstorming brings advantages to the creative process because the accumulation of ideas leads to the generation of more ideas, which eventually leads to a solution (OSBORN, 1962).

Another benefit of group brainstorming is that collective thinking tends to increase the associative power of participants (OSBORN, 1962). Also, according to the author, group work doubles the number of ideas generated concerning individual processes. Additionally, studies have shown that competition in group creation increases the effectiveness of mental work by about $50 \%$. Finally, according to Kelley and Littman (2005) apud Chammas (2018), brainstorming can be a starting point for innovation because it is fun, releases energy, and enables the participants quickly to produce results.

Considering the advantages of co-creation method and group brainstorming, it can be argued that the development of proposals for innovative products, such as artificial intelligence systems, can benefit from the collaborative creation approach. Using co- creation as a method, design workshops as an organized interaction platform, and group brainstorming as a collaborative creation technique, this article presents a study on the creation of interfaces for automated vehicles and how cocreation methods can benefit the design of these products.

\section{The automated vehicle's study}

Human error in driving vehicles is a significant problem for road safety. Worldwide, vehicle accidents kill about 1.3 million people a year (COSTLOW, 2018) and 90\% of these accidents are caused by human error (CHIELLINO et al., 2007 apud GOLD et al., 2013). Considering this scenario, the future implementation of automated vehicles, in which the automated driving system is responsible for driving the vehicle, is an essential alternative for the safety of drivers and pedestrians and to prevent social and economic damage to society.

Despite the great potential advantages of automated vehicles, some issues related to human factors in the use of this technology still prevail, as it is not yet possible to remove all the responsibility from the driver at its current level of development. This type of vehicle, with conditional automation (or level 3), makes the driver a user who must be receptive to the need to take over the vehicle's control in certain situations (SAE, 2013). These systems change the conventional roles of the interaction since the user no longer plays the role of a conventional driver who performs driving task all the time, nor is a passenger exempt from any responsibility to intervene.

The problem that arises from this new dynamic of interaction is that to perform the driving task, the driver must be in the so-called decision-making loop (MERAT et al., 2018). Merat et al. (2018) argue that to be in the decision-making loop, the driver must be in physical control of the vehicle (controlling the steering wheel, pedals) and monitoring dynamic changes in the driving environment, including actions related to the automated system. However, users tend to overestimate the automated driving system's capabilities and believe that the vehicle will handle all situations by itself (GOLD et al, 2015). Such overconfidence makes users complacent and distracted from the primary driving task, and may even lead to the engagement in secondary tasks (BOROJENI et al., 2016). This behavior has been observed as dangerous since it may take the driver 
out of the decision-making loop, therefore affecting the quality of the resumption of control (ZEEB et al., 2015; LOUW \& MERAT, 2017).

The issues in the new dynamics between driver and vehicle has already proved problematic. In May 2016, the first fatal accident involving the driving of an automated vehicle, a Tesla Model S, occurred (BURNS and SHULGAN, 2018). The driver was using the "Autopilot" feature of the Tesla Model S, launched seven months before the accident. The launch of this feature had generated controversy because the system did not clearly present the need for the driver to continuously pay attention to the road after turning the system on. According to investigations into the accident, the system was unable to recognize a truck crossing the road. Nevertheless, it was noted that the truck could have been identified by the driver about 10 seconds before the impact, giving him enough time to resume control. The lack of evidence of steering or breaking indicated that the driver might have taken no action to dodge the truck, suggesting that he was so confident in the "Autopilot" that he was not paying attention to the road (BURNS and SHULGAN, 2018).

Issues related to automated vehicles are linked to several factors, from human behavior to hardware and software technology. However, the failure to present information about the automated system can be fatal to the users of these vehicles. Effective presentation of information to the driver, therefore, can not only mitigate the effects of human factors on automated driving but can also help improve users' performance in interacting with these systems. To this end, NHTSA (2016), the U.S. traffic regulator, recommends presenting five-key essential items of information in the human-machine interface (HMI) of automated vehicles:

1) The system is functioning properly - that is, the system is off, but ready to be turned on;

2) The system is currently engaged in automated driving mode - that is, the system is engaged and adequately functioning;

3) The system is currently unavailable for automated driving - that is, the system is off and is not ready to be turned on;

4) The system is experiencing a malfunction with the automated vehicle system - that is, the system is engaged, but malfunctioning;

5) The system is requesting control transition from the automated vehicle system to the operator that is, the system is requiring the driver to intervene. This alert is also known as a Take Over Request (TOR);

Automated vehicles with conditional automation are an example of how advances in technology drastically change a task that human beings have been performing for decades: driving. As noted previously, this scenario poses a challenge for designers to design interfaces that keep up with the new dynamics of interaction while effectively communicate information. It is necessary to think of new ways to present status messages and TOR for users of automated driving systems through the system's interface. Thus, considering the benefits of group brainstorming, this article presents a study which aimed to create proposals of interfaces for automated vehicles, in two co-creation workshop sessions with designers.

\section{Method}

A co-creation workshop was conducted with professors and students of undergraduate and graduate programs in Design from PUC-Rio university's Department of Arts and Design. The objective of the workshop was to promote the creation of proposals for information design of system status and TOR in automated vehicles' interfaces. The workshop technique was chosen because it allowed the collective creation of solutions by Design experts. Participation was voluntary, and participants did not receive any financial compensation. A recruitment form was sent by email to the professors and published on social media for the students. The form asked for basic contact information and availability for the study.

As automated vehicles are far from the Brazilian market, there are no real users or customers available to participate in user research based on their experience with such products. However, all workshop participants were occasional drivers or passengers, being considered potential users of automated vehicles and able to empathize with future users. Thus, the sessions allowed designers to propose interfaces based on their design knowledge while thinking about their needs as general vehicle users, bringing their experiences to the proposals. Finally, the university was chosen as the environment for the study because it is an institution that brings together, in a single place, several Design experts who deal daily with innovation projects, information communication, and design research. 


\subsection{Procedure}

LEUI | Laboratório de Ergodesign e Usabilidade de Interfaces

The workshop was held in two independent sessions on May 20th and May 22nd, 2019. Each session lasted around one hour and a half. The first session had eight participants (three professors, two graduate students, and three undergraduate students), and the second one gathered nine designers (six professors, one graduate student, and two undergraduate students). The number of participants for the study is in accordance with Wilson (2013), which stated that groups for brainstorming should have three to ten participants. Two researchers mediated both sessions.

Participants arrived at the venue at the scheduled time, signed a consent form, and were comfortably accommodated. Following, participants were reminded of the research subject and the workshop's purpose. A brief presentation was made to expose the automated vehicles' concepts, the levels of automation, the research context, and the issues surrounding information presentation in automated vehicles. After that, the goal of the workshop was presented: "How to inform the driver of a partially autonomous car (level 3) about this information (the five-key information from NHTSA, 2016)?".

For all brainstorming sessions, paper, pencil, and colored pens were provided to participants, as can be seen in figure 1. Moreover, as recommended by Osborn (1963), participants were encouraged to value quantity over the quality of the ideas. The groups were also invited to express any idea that comes to their minds, independently on its plausibility. Furthermore, the participants were instructed not to criticize the proposals suggested by the group.

The two independent sessions were planned and conducted with different structures in order to obtain a wider variety of resulting proposals created by participants. A summary of the structure of both workshop sessions is presented in table 1 .

\begin{tabular}{r|ll}
\multicolumn{1}{c|}{ Stage } & Day 1 & Day 2 \\
\hline 1 & $\begin{array}{l}\text { Individual } \\
\text { brainstorming }\end{array}$ & Brainstorming in pairs \\
2 & $\begin{array}{l}\text { Group brainstorming } \\
\text { Presentation and } \\
\text { discussion of the } \\
\text { proposals created in } \\
\text { stage 1 }\end{array}$
\end{tabular}

Discussions of the proposals and their appropriateness to the workshop's goal

Additional time for the detailing and graphical representation of the proposals (in pairs)

Table 1 - Structure of the workshop's sessions

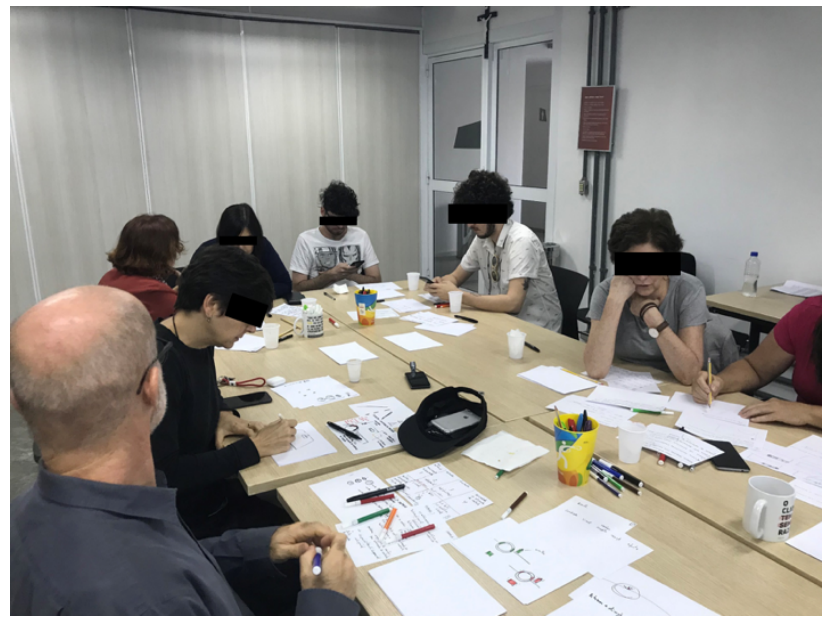

Figure 1 - Second session of the workshop

In the first session, after the initial presentation, an individual round of brainstorming was conducted. Participants had 15 minutes to individually elaborate as many proposals as possible for the presentation of status messages and TOR to drivers. After this stage, a group brainstorming was in place for 20 minutes. The participants were encouraged to share and discuss the ideas created in the first round to generate new proposals. This stage was based on Osborn's recommendation (1962, apud Chammas, 2018) to let the brainstorming participants detail and combine ideas. In the final round, the designers had 30 minutes to review the created proposals and discuss which ones they considered to best achieve the workshop's goal and why. Finally, the moderators thanked the designers for their participation and gathered the proposals for future analysis.

In the workshop's second session, the initial brainstorming round was conducted in pairs rather than individually to encourage the discussion for the creation of ideas. Furthermore, it was observed that the group brainstorming stage in the first section resulted solely in a presentation of the ideas, and not in the collective creation of new proposals. Thus, for session two, this stage was replaced by the presentation and discussion of the ideas created in pairs, and the final discussion stage was replaced by an additional time to represent the proposals graphically. This stage was added because it was 
observed in session one that participants'

representations of the proposals were not detailed or specific about the interfaces' functioning.

\subsection{Proposals' analysis}

The proposals were analyzed in three steps:

1) For the proposals' analysis, a review of them was initially made to identify, in a bottom-up approach, how ideas could be clustered. From this review, the proposals were categorized into: proposals that specified only where the information should be displayed; proposals that specified only how the information should be presented; proposals that specified both how and where information should be displayed; and proposals that, besides specifying how and where information should be presented, also considered a sequence in the presentation of the information, when the participants created proposals for each of the five-key information requested in a sequence correlated.

2) After this categorization, the proposals were classified according to the type of information presented (regarding the five-key information from NHTSA); the modality of information presentation (visual, auditory or vibrotactile); the format the information is presented, when appropriate and; the place where information is displayed, where applicable.

3) Finally, in order to better visualize, register, and organize the ideas, the proposals were then registered in a digital frame created for this study (figure 2). The frame was created based on a survey of all places of information presentation identified in step 2 of the analysis.

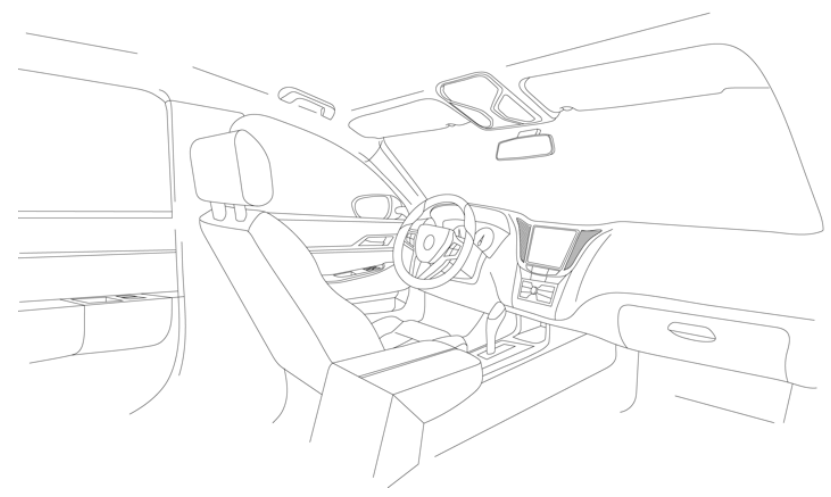

Figure 2. Frame developed to digitally register the proposals created in the workshop sessions.

\section{Results}

The first session of the workshop resulted in 59 interface proposals, and the second session in 46, totalizing 105 ideas created by the participants. Due to the differences in the two sessions' structures, the first session had a larger number of less detailed proposals, and the second session had a smaller number of ideas, yet richer in detail and visual representation. The interfaces created in the second session also tended to present more than one piece of information sequentially, as in figures $3,4,5$ and 6 (e.g., A message informing the driver that the system is engaged followed by a malfunctioning message). The resulting proposals were organized into the before mentioned categories (table 2):

\begin{tabular}{r|lllc} 
Categories & Where & How & $\begin{array}{l}\text { Where } \\
\text { and } \\
\text { How }\end{array}$ & Sequence \\
\hline $\begin{array}{r}\text { Number of } \\
\text { ideas }\end{array}$ & 6 & 11 & 32 & 56
\end{tabular}

Table 2 - Number of ideas per category

As for the type of message displayed by the proposals, 15 interfaces proposals presented messages for system "functioning properly", 13 for "currently engaged in automated driving mode", 10 for "automated driving unavailable", 14 for "experiencing a malfunction with the AV system" and 51 for TORs. These results show that the workshops' participants focused heavily on presenting messages of transition of control on the HMI.

Concerning the modality for information presentation, the proposals were classified as illustrated in table 3.

\begin{tabular}{l|lll}
\multicolumn{1}{l}{ Modality } & Visual & Auditory & Haptic \\
\hline $\begin{array}{l}\text { Number of } \\
\text { ideas }\end{array}$ & 62 & 6 & 11 \\
Modality & $\begin{array}{l}\text { Visual and } \\
\text { auditory }\end{array}$ & $\begin{array}{l}\text { Visual and } \\
\text { haptic }\end{array}$ & $\begin{array}{l}\text { Visual, } \\
\text { haptic and } \\
\text { auditory }\end{array}$ \\
$\begin{array}{l}\text { Number of } \\
\text { ideas }\end{array}$ & 14 & 2 & 5
\end{tabular}

Table 3 - Number of ideas per modality of information presentation 

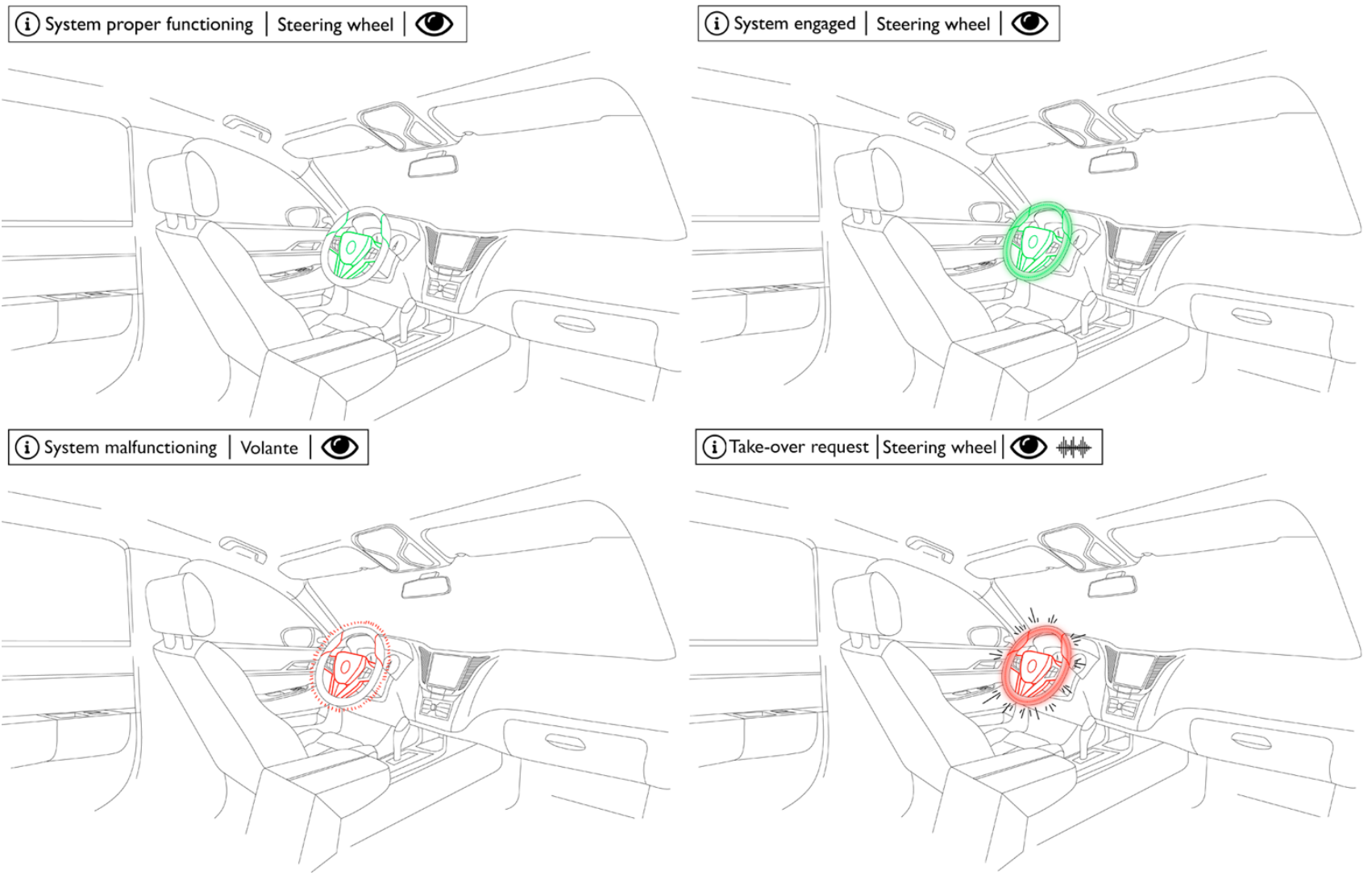

Figures 3, 4, 5 and 6. Proposal which presents the information sequentially. Figure 3 (top-left) communicates that the system is functioning properly by applying the green color only to details on the steering wheel; Figure 4 (top-right) shows that the system is engaged by displaying green lights on all of the steering wheel; Figure 5 (bottom-left) presents a malfunctioning message to the driver by applying red blinking light on details of the steering wheel; Figure 6 (bottomright) informs the driver of a TOR by vibrating the steering wheel and by displaying red lights on the whole steering wheel.

The majority of the interfaces proposed to present information through the visual channel (as in figures 3,4 , and 5). The use of different modalities was also applied, especially for TORs (figures 6, 7 and 8). Amongst the interfaces that presented a TOR, some proposals suggested to display the information gradually, varying the urgency of the messages by combining two or more modalities (figures 5 and 6). The use of multimodality was also observed for malfunctioning messages (figure 9). As shown in table 3 , the majority of the multimodal interfaces combined the visual channel with an additional channel.

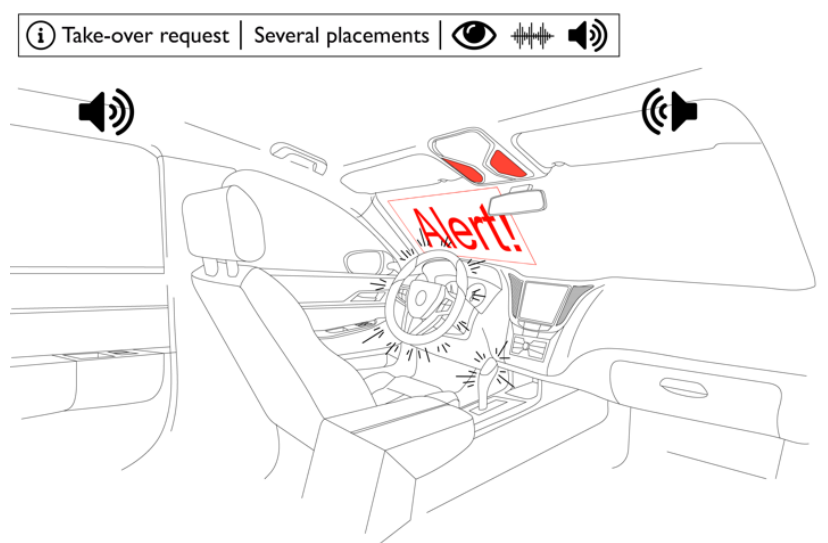

Figure 7. The proposal presents a TOR through a combination of vibrotactile cues on the steering wheel, auditory cues, red lights in the roof lights, and a an "Alert!" message on the windshield. 


\section{(i) Take-over request | Driver's seat; Roof lights | $\mathcal{O}$}

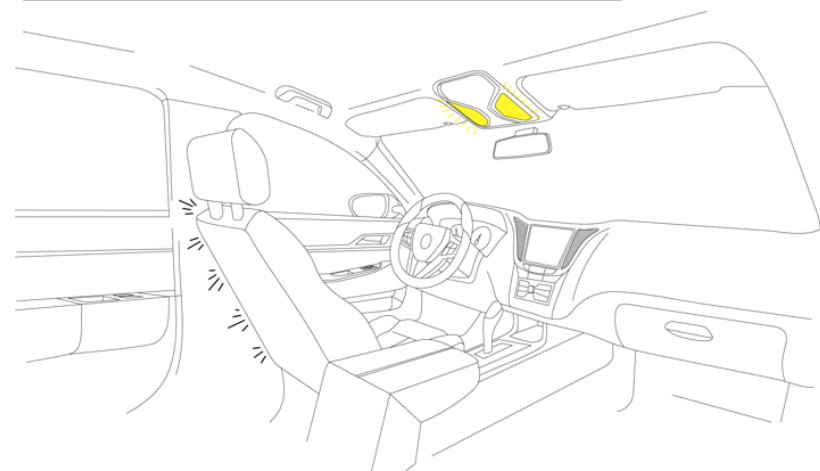

Figure 8. The proposal presents a TOR through vibrotactile cues on the driver's seat and by blinking the roof lights.

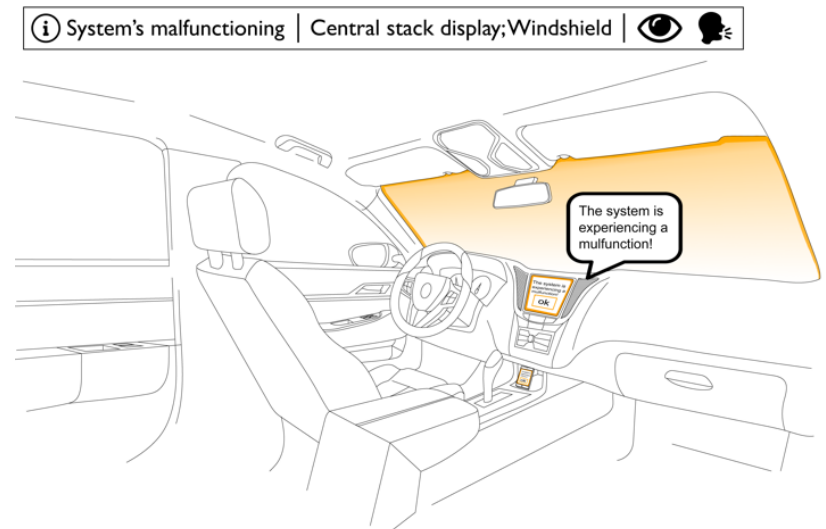

Figure 9. The proposal presents the message about a system's malfunctioning in a central stack display e though a projection of the orange color on the windshield. The messege is also presented through voice.

The placements chosen by participants to allocate their interfaces were (figure 7): driver's seat; steering wheel; instrument cluster; central stack display; windshield; rearview mirror; roof lights; windshield frame; a VR (virtual reality) glasses for the driver (figure 11); driver's smartphone (figure 12); and gear shifter. Figure 10 illustrates the number of ideas that proposed to place interfaces at each of these locations:

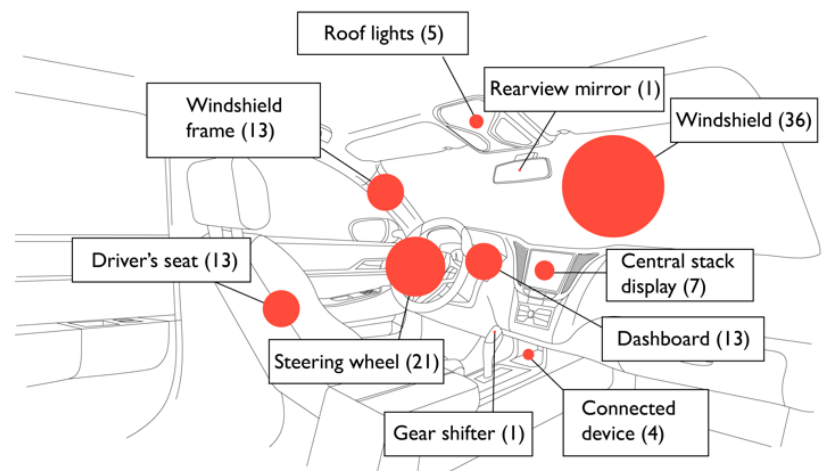

Figure 10. Number of proposals which presented an information for each placement in the vehicle.

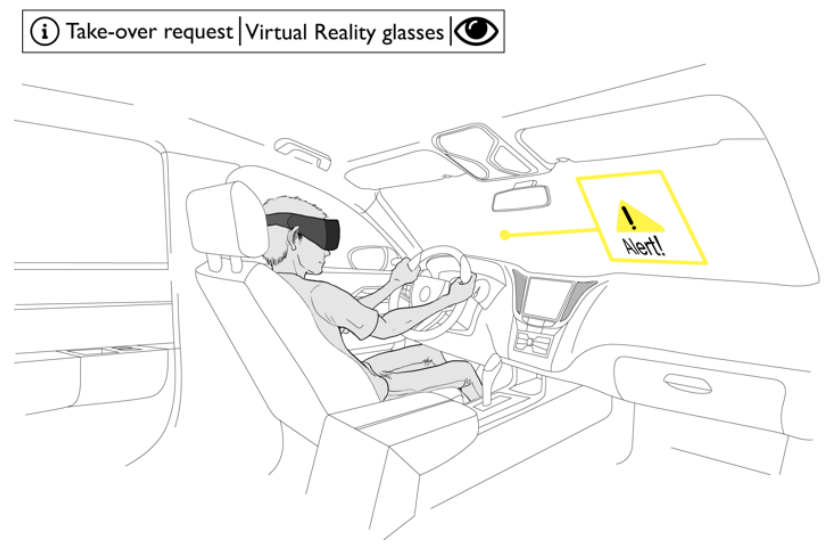

Figure 11. The proposal presents a TOR through virtual reality glasses.

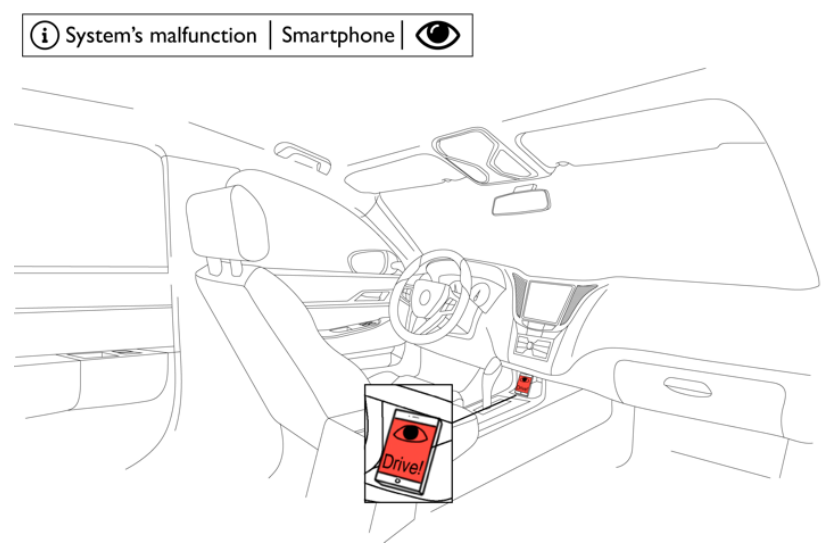

Figure 12. The proposal presents a TOR on the driver's smartphone.

The proposals were also analyzed in terms of the format of the information presentation. The visual messages were presented through: colorcoding (figure 13); text and number (figure 14); icons (figure 15); peripheral lights (figure 16); blinking elements (figure 15). As for the auditory interfaces, information was presented through: voice messages (figure 9); earcons (abstract auditory cues; BLATTNER et al., 1989; figure 17); and auditory icons, which mimic real-world sounds to represent an interaction (ROGINSKA et al., 2013; e.g., a horn sound to represent a TOR). Finally, haptic interfaces presented messages by using vibrotactile cues (figure 18). 


\section{(i) Take-over request $\mid$ Windshield $\mid \bigcirc$}

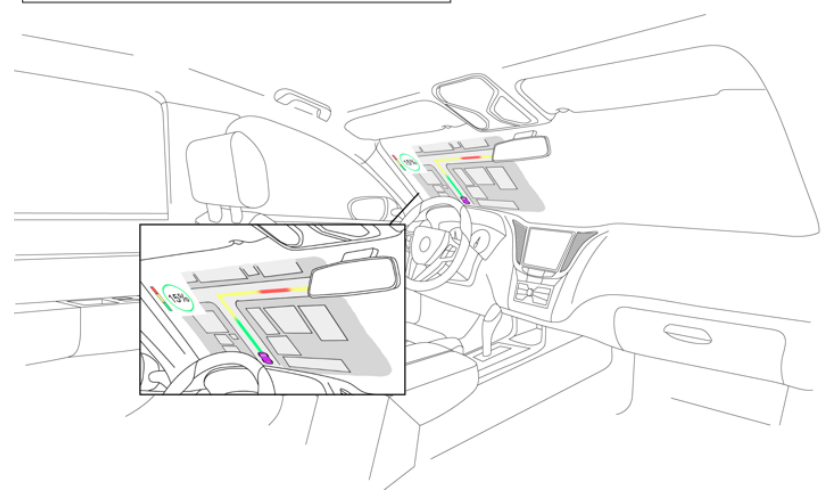

Figure 13. Proposal which informs the driver of the probability of a TOR. The interface displays this information through icons in the windshield that represent the road environment. The interface applies color codes to represent different probabilities of TOR: green for low probability, yellow for median probability, and red for a high probability of TOR.

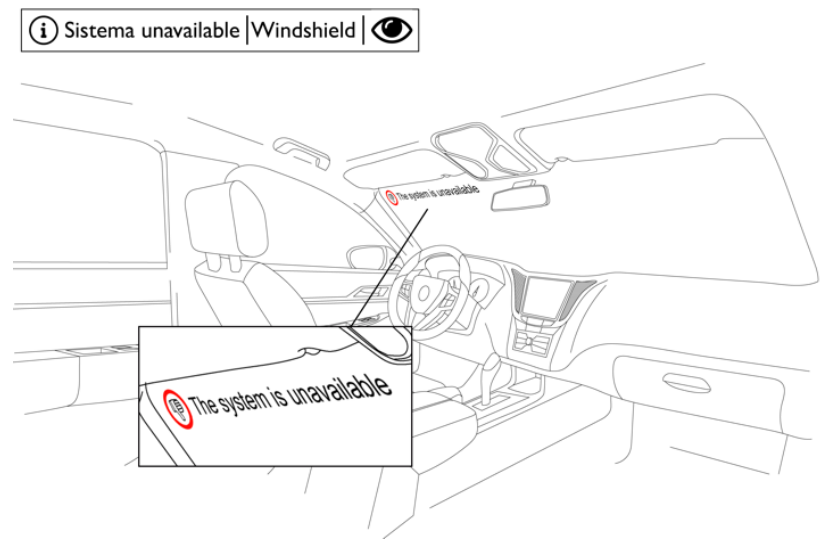

Figure 14. Proposal which inform the driver that the system is unavailable through a verbal message and an icon on the windshield

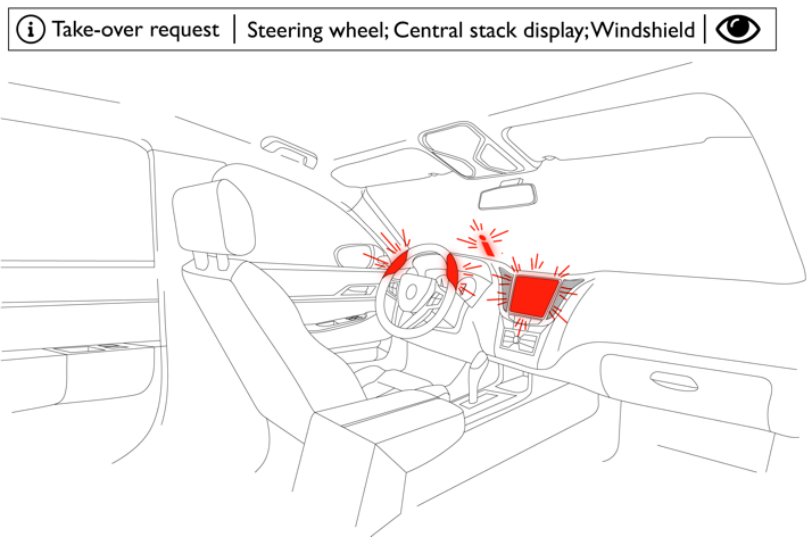

Figure 15. The proposal presents the TOR by filling the central stack display with red lights, by lighting up parts of the steering wheel in red and though a projection of an avatar on the windshield. All elements blink.

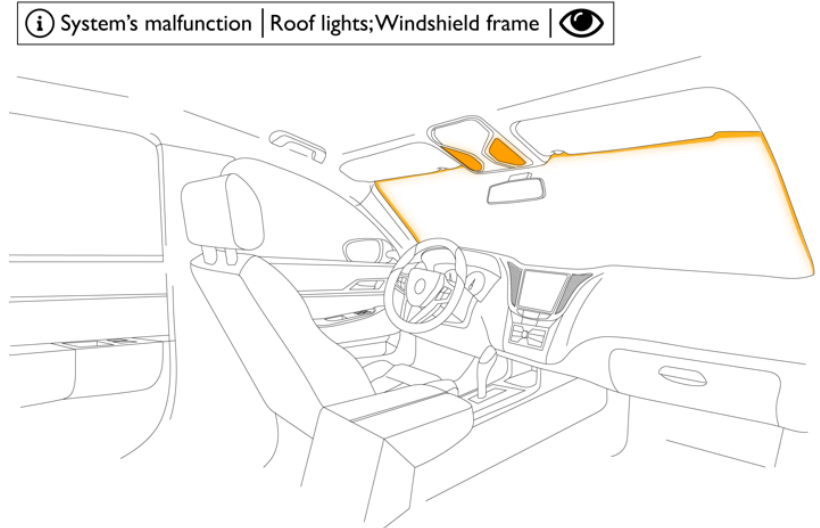

Figure 16. The proposal presents a malfunctioning message through peripheral orange lights on the windshield's frame and roof lights.

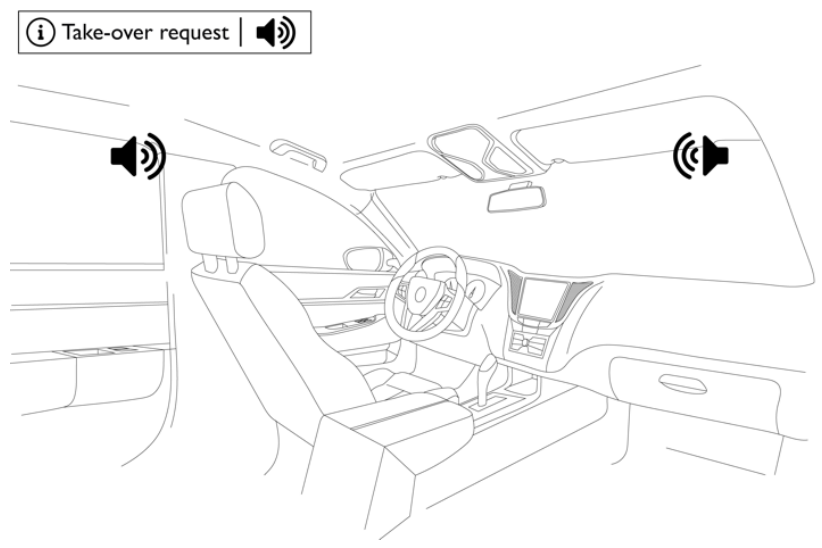

Figure 17. The proposal presents a TOR through an auditory cue.

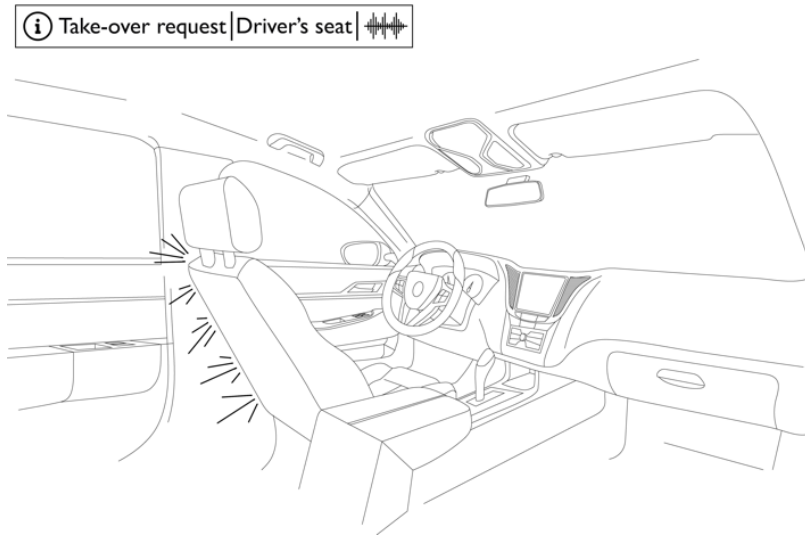

Figure 18. The proposal presents a TOR through vibrotactile cues on the drive's seat.

\section{Conclusion}

Due to the increasing development of new technology, such as artificial intelligence systems, 
PUC-Rio Pontifícia Universidade Católica do Rio de Janeiro Departamento de Artes \& Design | PPGDesign

the dynamics of users' interactions with products is changing. This scenario poses the challenge to interaction designers to re-think the ways new interfaces are created, aiming to appropriately fulfill users' needs and convey the products' information. In order to design interfaces to such novel technologies, the co-creation method is an approach that offers several benefits to interaction designers.

This paper aimed to assess the benefits of cocreation methods through a case study, which gathered students and professors of Design in two co-creation workshop sessions for the creation of proposals for interfaces for automated vehicles.

The differences in the workshop sessions' structures resulted in variations in the proposals created by the participants. In the first session, the designers had two rounds of brainstorming, which culminated in a larger number of ideas. Nevertheless, the participants' representations of their ideas were less detailed, and the proposals tended to present only a piece of information about the automated vehicle's system - mainly TOR. Amongst the first sessions' ideas, the forms of information presentation varied, but the quality of the interfaces was inferior.

As for the second session of the workshop, in which only one brainstorming round occurred, a decreased number of ideas was observed. However, due to the extra time given to the participants to work on their ideas in the second session, the resulting proposals were more thoroughly represented and were designed to present more than one piece of information. Thus, proposals created in the second session had a higher quality in terms of information integration, despite the smaller number of ideas.

The difference in quantity and quality of proposals created in the two sessions was due to the sessions' structures. Such results indicate that it is possible to apply different approaches in order to attain varied outcomes when conducting co-creation techniques. Moreover, despite the difference in the workshop structures, the richness of collective production was observed in both sessions. The discussions and group ideation actively contributed to the proposals' creation, as it allowed participants to exchange their experiences as drivers and passengers, and collectively generate ideas. Furthermore, the plurality of the group brought benefits to the process since participants had different backgrounds in Design (e.g., graphic design, product design, digital media, fashion).
As for the created proposals, although the placements chosen for the presentation of information were not new, the ways of information presentation were innovative. As illustrated in figure 8 , some proposals mixed already existing elements such as GPS navigation system routes and Head-Up Displays (HUD) - to present information (probability of TOR) in a novel way: risk preview overlapped with the vehicle's route. Moreover, the participants sought to respect design principles in their proposals, applying icons, color codes, and even modalities other than the visual.

The workshops' results point to the advantages of gathering professionals with varying levels of experience and areas of knowledge in Design to collectively create interfaces' concepts. As the participants were knowledgeable of different areas of Design, their proposals naturally applied the Design principles necessary to present information on an interface. Furthermore, since the designers also were potential users of automated vehicles - as drivers or passengers - they were able to translate their own experiences into the proposals. Thus, the interface concepts created in the workshop were the results of a creative process that combined participants' experiences with vehicles with their academic and professional knowledge of Design.

Finally, it is necessary to point out that the chosen environment for the workshop - the University brought advantages to the process. As the University is an institution that conducts research and development of innovation and technology daily, professors and students were aware of what is plausible and viable to be developed. Moreover, the designers were used to co-creation techniques such as Design workshops and brainstorming and were able to generate ideas free from critics and judgments. Additionally, the University is not as constrained by deadlines, sales goals, or budgets as the manufacturers are. Applying methods of alternative production and simulation, the development of research for innovation at Universities is of great value to advances in the market.

\section{References}

BLATTNER, M. M.; SUMIKAWA, D. A.; GREENBERG, R. M. Earcons and icons : their structure and common design principles. HUMANCOMPUTER INTERACTION, v. 4, p. 11-44, 1989. 
PUC-Rio Pontifícia Universidade Católica do Rio de Janeiro Departamento de Artes \& Design | PPGDesign

LEUI | Laboratório de Ergodesign e Usabilidade de Interfaces

BOROJENI, S. S., e colab. Assisting Drivers with Ambient Take-Over Requests in Highly Automated Driving. In AutomotiveUI 2016 - 8th International Conference on Automotive User Interfaces and Interactive Vehicular Applications (pp. 237-244), 2016. p. 237-244.

BURNS, L. D., SHUlGAN, C., Autonomy: The quest to build the driverless car - and how it will reshape our world. New York, New York, USA: HarperCollins, 2018.

CHAMMAS, A. S., QUARESMA, M., MONT'ALVÃO, C., A produção criativa de crianças no brainstorming de desenvolvimento de inovações em design de produtos digitais. Rio de Janeiro, 2018. 242p. Tese de Doutorado Departamento de Artes \& Design, Pontifícia Universidade Católica do Rio de Janeiro.

COSTLOW, T., Detecting Pedestrians.

Autonomous Vehicle Engineering, n. May, p. 6-8, 2018.

FROST \& SULLIVAN, Global Autonomous Driving Market Outlook, 2018, 2018. Disponível em: https://info.microsoft.com/rs/157-gqe382/images/k24a-

2018\%20frost $\% 20 \% 26 \% 20$ sullivan $\% 20$ \%20global\%20autonomous\%20driving\%20outlook. pdf Acesso em 12 de setembro de 2019.

GOLD, C., DAMBOCK, D., LORENZ, L., BENGLER, K., "Take over!" How long does it take to get the driver back into the loop?, In: Proceedings of the Human Factors and Ergonomics Society $57^{\text {th }}$ Annual Meeting, San Diego, USA, 2013.

GOLD, C., e colab. Trust in Automation - Before and After the Experience of Take-over Scenarios in a Highly Automated Vehicle. In Procedia Manufacturing (Vol. 3, pp. 3025-3032). 2015. p. 3025-3032.

INSIDER, Microsoft exec: 'AI is the most important technology that anybody on the planet is working on today', 2016. disponível em: acesso em 12 de setembro de 2019.

LOUW, T., MERAT, N., Are you in the loop? Using gaze dispersion to understand driver visual attention during vehicle automation.

Transportation Research Part C: Emerging
Technologies, v. 76, p. 35-50, 2017.

MARTIN, B., HANINGTON, B., Universal Methods of Design: 100 ways to research complex problems. Beverly, MA: Rockport, 2012.

MERAT, N., et al., The "Out-of-the-Loop" concept in automated driving: proposed definition, measures and implications, In: Cognition, Technology \& Work, Springer, 2018.

NHTSA. Federal Automated Vehicles Policy: Accelerating the Next Revolution In Roadway Safety. U.S. Department of Transportation. [S.1: s.n.], 2016.

OSBORN, A. F., O poder criador da mente: Princípios e processos do PENSAMENTO CRIADOR e do "BRAINSTORMING", São Paulo: IBRASA, 1962.

PRAHALAD, C. K. e RAMASWAMY, Venkat. Co-creation experiences: The next practice in value creation. Journal of Interactive Marketing, v. 18, n. 3, p. 5-14, 2004. Disponível em: $<$ http://dx.doi.org/10.1002/dir.20015>.

RAMASWAMY, Venkat. Innovation through Cocreation: Engaging Customers and Other Stakeholders. 2011, Philadelphia, PA: William \& Philly's Mack Center for techological innovation, 2011. p. 5-7.

SANDERS, E., STAPPERS, P., Co-creation and the new landscapes of design. CoDesign, v. 4, n. 1, p. 5-18, 2008.

\section{SOCIETY OF AUTOMOTIVE ENGINEERS}

INTERNATIONAL. Taxonomy and Definitions for Terms Related to Driving Automation Systems for On-Road Motor Vehicles. SAE International. Warrendale: [s.n.], 2018.

STATISTA, Digital Economy Compass 2018. 2018, Disponível em:

https://static2.statista.com/download/pdf/digital eco nomy compass_2018.pdf Acesso em 29 de abril de 2019.

TRADE MACHINES, Get ready for robolution!, 2019, Disponível em:

http://trademachines.com/info/robolution/ Acesso em 12 de setembro de 2019. 
TURIERA, T., CROS, S., CO business: 50 examples of business collaboration. [S.1.]:

Infonomia, 2013. Disponível em:

$<\mathrm{http}: / /$ www.infonomia.com $>$.

WILSON, C., Brainstorming and Beyond. [S.1.]:

Elsevier, 2013. Disponível em:

$<$ https://linkinghub.elsevier.com/retrieve/pii/C20120

035338>.

ZEEB, K., BUCHNER, A., SCHRAUF, M., What determines the take-over time? An integrated model approach of driver take-over after automated driving. Accident Analysis and Prevention, v. 78, p. 212-221, 2015.

\section{Ackowledgements}

To CNPq for financing the student's PIBITI grants. 